\title{
Male and female sexual dysfunction in diabetic subjects: Focus on new antihyperglycemic drugs
}

\author{
Giovanni Corona ${ }^{1} \cdot$ Andrea M. Isidori $^{2} \cdot$ Antonio Aversa $^{3} \cdot$ Marco Bonomi $^{4,5} \cdot$ Alberto Ferlin $^{6} \cdot$ Carlo Foresta $^{7}$. \\ Sandro La Vignera ${ }^{8} \cdot$ Mario Maggi $^{9} \cdot$ Rosario Pivonello $^{10} \cdot$ Linda Vignozzi $^{9} \cdot$ Francesco Lombardo $^{2}$
}

Published online: 20 December 2019

(C) Springer Science+Business Media, LLC, part of Springer Nature 2019

\begin{abstract}
The association between diabetes mellitus (and its micro- and macro-vascular complications) and erectile dysfunction is widely known and the presence of hypogonadism may further complicate sexual dysfunction and quality of life, given the association between hypogonadism and reduced libido, ejaculatory disorders, and depressive symptoms. However, the recent introduction of novel antidiabetic agents with a wide range of mechanism of action may have a significant impact both on male and female sexuality directly (by inducing side effects as urinary tract infections) and indirectly (improving metabolic status and reducing diabetes complications behind sexual dysfunctions). To date only few papers are reporting the sexual effects of these treatments and, often, these are not comparable in their results. Conversely, female sexual dysfunctions are somehow under-investigated. Data on prevalence is heterogeneous and specific pathogenic mechanisms, as well as the burden of psychological factors, are still heatedly debated. The aim of this narrative review is to summarize current knowledge and stressing out the need to diagnose male and female sexual dysfunctions also in light of the impact of treatments with novel antidiabetic agents. This would highlight the still unmet needs for sexual care in a diabetes care setting and could represent an incentive for future discussions, as well as a required theoretical starting point for studies on this subject.
\end{abstract}

Keywords Diabetes mellitus $\cdot$ Sexual dysfunctions $\cdot$ Erectile function $\cdot$ Female sexual dysfunctions $\cdot$ Antidiabetic agents

\section{Introduction}

Diabetes mellitus (DM) represents one of the leading causes of mortality worldwide, with an estimated related death of at least 1.3 million in 2013 [1]. prevalence of 382 million people with DM worldwide has been reported in the same year. Current projections suggest that this number will reach 592 million by the year $2035[2,3]$. The association between DM

Francesco Lombardo

francesco.lombardo@uniroma1.it

1 Endocrinology Unit, Medical Department, Maggiore-Bellaria Hospital, Largo Nigrisoli 2, 40133 Bologna, Italy

2 Department of Experimental Medicine, Sapienza University of Rome, Rome, Italy

3 Department of Experimental and Clinical Medicine, "Magna Graecia" University, Catanzaro, Italy

4 Department of Clinical Sciences and Community Health, University of Milan, Milan, Italy

5 IRCCS Istituto Auxologico Italiano, Department of Endocrine and Metabolic Diseases and Lab of Endocrine and Metabolic Research, Milan, Italy and erectile dysfunction and a decrease in libido, or loss of a sex drive both in male and female is widely known and the presence of hypogonadism may further complicate sexual dysfunction and quality of life, given the association between hypogonadism and reduced libido, ejaculatory disorders, and depressive symptoms.

Type 2 DM (T2DM) represents the most common form of $\mathrm{DM}$, showing the highest prevalence increase, due to its

6 Department of Clinical and Experimental Sciences, Unit of Endocrinology and Metabolism, University of Brescia, Brescia, Italy

7 Department of Medicine, Unit of Andrology and Reproductive Medicine, University of Padova, Padova, Italy

8 Department of Clinical and Experimental Medicine, Policlinico " $\mathrm{G}$. Rodolico", University of Catania, 95123 Catania, Italy

9 Endocrinology Unit, Department of Experimental Clinical and Biomedical Sciences "Mario Serio", University of Florence, Viale Pieraccini 6, 50139 Florence, Italy

10 Division of Endocrinology, Università degli Studi di Napoli "Federico II", Naples, Italy 
association with obesity [4-6]. Intensive glucose control provided a significant reduction in the incidence of cardiovascu$\operatorname{lar}(\mathrm{CV})$ events and mortality or total mortality in patients with advanced T2DM, thus suggesting that glucose lowering is not enough [7-10].

Several new classes of drugs for T2DM treatment have recently been introduced in the clinical practice. Among them, the sodium-glucose type 2 co-transporter inhibitors (SGLT2i) represents the last category of oral antihyperglycemic agents. Their anti-diabetic effect is based on the inhibition of glucose reabsorption in the proximal renal tubule thus determining an increase in urinary excretion of glucose and a reduction of its circulating levels [11]. Both the American Diabetes Association (ADA) and the European Association for the Study of Diabetes (EASD) recommended the use of SGLT2i as second-line drugs after failure of fist-line regimes or in metformin intolerant patients [12]. These drugs seem very promising as phase III studies have shown a high degree of tolerance and a higher efficacy on glucose control compared sulfonylurea or dipeptidyl peptidase IV inhibitors (DPP4i) [13]. However, the most interesting data concerns the effects of cardiovascular (CV) protection. Accordingly, welldesigned controlled trials on wide sample cohorts demonstrated the efficacy of empagliflozin, canagliflozin and dapagliflozin in reducing the incidence of major $\mathrm{CV}$ events (MACE), total and CV mortality and the incidence of hospitalizations for heart failure (HF) [14-16]. Conversely, DPP4i have been shown a neutral effect on CV outcomes, whereas $\mathrm{CV}$ protection has been also documented with the use of glucagon-like peptide-1 receptor agonists (GLP-1RA) [17].

Sexual dysfunctions represent a wide spectrum of disorders such as erectile dysfunction (ED), premature or delayed ejaculation, anejaculation or retro-ejaculation in men, genital arousal disorder in women and hypoactive sexual desire or anorgasmia in both (Table 1). Despite their prevalence is not negligible in the diabetic population, sexual disorders remain often underdiagnosed and undertreated [18, 19]. The presence of hypogonadism, which diabetic patients are exposed to, may further complicate sexual dysfunctions and quality of life in

Table 1 DSM-5 classification of sexual dysfunctions men, due to its association with reduced libido, ejaculatory disorders, and depressive symptoms [20]. In addition, much evidence suggests that ED can represent an early marker of forthcoming CV diseases (CVD), particularly in the diabetic population [21] and, thus, the research of ED in DM patients would be relevant for CVD prevention. Importantly, limited attention has been paid by available guidelines on diagnosis and management of sexual disorders in diabetic patients so far. Also, the recent introduction of novel antihyperglycemic agents, with a wide range of mechanisms of action, may result in a significant impact on both male and female sexuality either directly, by inducing side effects such as urinary tract infections, or indirectly, by improving metabolic status and reducing diabetes complications and $\mathrm{CV}$ risk, behind sexual dysfunctions.

The specific impact of these novel antihyperglycemic agents on sexuality has been poorly investigated. Therefore, the aim of this narrative review is to summarize the available evidence linking DM and sexual dysfunction, particularly focusing on the impact of new antihyperglycemic treatments.

\section{Impact of DM on male sexual function}

\subsection{Erectile dysfunction}

The prevalence of ED among subjects with DM is quite variable and is tightly related to DM duration, degree of obesity, and micro- and macro-vascular complications [22, 23]. Another factor tightly associated with T2DM is hypogonadism [20]. In patients with T2DM, low testosterone (T) may further complicate sexual dysfunction and quality of life, due to its association with reduced libido, ejaculatory disorders, and depressive symptoms [see below; 20,23]. Similarly, genito-urinary infection, quite common in the diabetic population, can further complicate the clinical setting [23; see below]. Fedele et al. [22] carried out the largest study on this topic, including 9869 male diabetic patients (age range, 20-69 years), randomly selected from 178 diabetes centers in Italy. The prevalence of ED among those with type $1 \mathrm{DM}$ (T1DM) was $26 \%$ versus $37 \%$ among those with T2DM; however, the difference was reduced when age was considered in a multivariate model [22]. More recently, Corona et al., [23] investigated the prevalence of ED in a large series of men with recently ( $<2$ years) diagnosed with DM. Among 499 subjects enrolled from 27 Italian diabetes centers, the authors reported mild ED in $19.4 \%$, mild-to-moderate in $15.4 \%$, moderate in $10.4 \%$, and severe in $21.6 \%$ of patients [23]. Finally, a meta-analysis including 145 studies and 88,577 men (mean age: $55.8 \pm 7.9$ years), showed an overall ED prevalence of $52.5 \%$ (95\% CI, 48.8 to 56.2), after adjusting for publication bias, being $37.5 \%$ in T1DM and $66.3 \%$ in T2DM [19]. In other terms, the same study documented that DM was 
associated with 3.5-fold increased risk of ED when compared to healthy controls. In addition, as expected, the authors reported that the concomitant prevalence of hypertension increased the risk.

Fewer studies have investigated the incidence of ED in DM. Fedele et al., [24] prospectively evaluated a subgroup of 1010 subjects without ED on enrolment up to 2.8 years on average, showing an incidence of ED of 68 cases/1000 subjects per year. Similar results were published around the same time by the Massachusetts Male Aging Study (51 cases/ 1000 subjects per year) [25]. De Berardis et al. [26], in another Italian study enrolling 670 men with T2DM followed every 6 months for up to 3 years, reported a higher incidence (166.3 per 1000 person-years). Conversely, a lower incidence (25/ 1000 person-years) was reported by Klein et al. [27] in a 10year cumulative US study in 264 T1DM men who were less than 30 years of age at diagnosis of diabetes.

Despite this evidence, the presence of ED in diabetic men is still poorly evaluated in routine clinical practice. Accordingly, a Danish study reported that only $33 \%$ of men with T2DM reported that their general practitioner had brought up sexuality in the consultation [28]. Similar results were more recently reported by Bjerggaard et al. [29], who showed that about $50 \%$ of sexually inactive men with T2DM declared that their sexual life did not meet their sexual needs. Since ED represents an early marker of forthcoming CVD particularly in the diabetic population [21], recognizing this symptom might motivate diabetic men to improve their metabolic control and treatment adherence.

\subsection{Hypogonadism}

Male hypogonadism is estimated to affect between $20 \%$ and $64 \%$ of men with T2DM, depending on the population characteristics [30, 31]. Longitudinal data have clearly demonstrated a bidirectional relationship linking hypogonadism and T2DM. Meta-analysis of the available data showed that subjects who developed T2DM at follow up had lower total T level at baseline $(-1.65[-3.01 ;-0.29] \mathrm{nmol} / \mathrm{L})$, when compared to controls [32]. In addition, the analysis of data from 1306 men included in the database of the Health Management Center in Taiwan, showed that DM and prediabetes condition significantly increased the risk of hypogonadism (total $\mathrm{T}<$ $10.4 \mathrm{nM}$ ) at follow up [33].

The specific mechanisms underlining the association between insulin insensitivity, T2DM and androgen deficiency are not completely understood. Either central or peripheral mechanisms have been considered [30, 31]. Increased body fat represents, most probably, the major player, and the first pathogenic step, in impairing the hypothalamic-pituitary activity. Longitudinal data from European Male Aging Study, including more than 2000 community-dwelling men, with a median follow up time of 4.3 years, have documented that obesity at baseline, and weight gain during the follow up, were the best predictors of the development of secondary hypogonadism [34]. In addition, lean men, as well as those who lost weight, were more prone to recover from secondary hypogonadism [34]. Animal data are in line with these observations. In a rabbit model of metabolic syndrome (MetS) and hypogonadotropic hypogonadism - obtained by feeding animals with a high fat diet for 12 weeks - it was demonstrated that metabolic derangements are able to induce a hypothalamic inflammation, leading to GnRH secretion impairment, totally restored by physical activity and weigh loss [35]. Different peripheral mechanisms have also been advocated. Other animal models have suggested that hypogonadism can induce insulin resistance in skeletal muscle, via androgen receptor (AR)-dependent mechanisms, involving a decreased peroxisone proliferator-activated receptor $\gamma$ co-activator $\alpha$, which in turn promotes mitochondrial biogenesis and skeletal muscle oxidative fibers [36]. In line with these data, Kelly et al., [37] showed that testicular feminized mice (Tfm), which are characterized by very low T level and impaired AR, displayed significantly reduced GLUT 4 and glycolitic enzymes in muscle.

Androgens can profoundly affect all steps of male sexual response cycle [38-40]. Accordingly, in hypogonadal men, T replacement therapy can improve all aspects of male sexual function, although its role in more complicated form of arteriogenic ED, such as in DM, is less evident and revised elsewhere [38-40]. Similarly, several non-controlled observational data have documented that TRT can improve metabolic control in T2DM. However, data from randomized controlled trials (RCTs) are more conflicting and revised elsewhere [41].

\subsection{Effects of new anti-diabetic drugs on male sexuality and hypogonadism}

The knowledge of the effects of the new anti-diabetic drugs including DPP4i, SGLT2i, and GLP1RA on male sexual and gonadal function is so far limited. Indeed, only few studies reported the effect of these therapies on $\mathrm{T}$ levels and sexual function. In addition, the available data were collected in different subset of diabetic patients and thus not comparable in their results.

Indirect evidence, mainly derived from studies performed in animal models, suggests that DPP4i might improve erectile function in T2DM patients, based on their potential effect to promote vascular repair and endothelial function. In a mouse model of hind limb ischemia, DPP4i markedly increased the release and mobilization of circulating endothelial progenitor cells from bone marrow, through an eNOS-related pathway [42]. In addition, DPP4i might indirectly improve endothelial function, through pituitary adenylate cyclase-activating polypeptide (PACAP), a peptide isolated from the hypothalamus, which may enhance gonadotropin release, and, subsequently, sex steroids level, and may exert vasorelaxant effects 
mediated by VEGF [43]. Finally, DPP4i have been shown to slow down atherogenesis [44].

Limited positive outcomes are also available for SGLT2i. In animal model of T2DM-associated erectile dysfunction, an experimental study demonstrated that short-term chronic treatment with empagliflozin, significantly improved erectile performance in response to electrical stimulation of the cavernous nerve, by increasing the nitrergic relaxation of erectile tissue [45]. Few experimental and clinical studies provided encouraging results on the potential effectiveness of GLP1RA in improving sexual symptoms in T2DM patients, probably mediated by the positive effects on gonadal function, visceral adiposity, and $\mathrm{T}$ levels. One study in an aging mouse model demonstrated that treatment with exenatide increased testis weight and volume, as well as T levels [46]. Similarly, a recent 12-week interventional study in obese T2DM patients demonstrated that short-term combined treatment with exenatide and metformin significantly increased total $\mathrm{T}$ levels and sexual function, being more effective than glimepiride-metformin combination [47]. As expected a more pronounced effect was reached in patients who had a greater weight loss, and correlation analysis clearly showed that changes in waist circumference alone explained about $20 \%$ of the variance in T levels, therefore indicating mediation by the metabolic effects [47]. In line with these data, liraglutide was shown to improve either levels or sexual function in patients with obesityassociated hypogonadism, poor responders to lifestyle modifications [48], and to potentiate the effects of TRT and metformin on erectile dysfunction, in T2DM obese patients with hypogonadism [49]. (See Table 2 and Fig. 1).

\section{Impact of DM on female sexual function}

\subsection{Female sexual dysfunctions}

Sexual dysfunction (SD) is an under-investigated complication of diabetes not only in male but also in female patients. The prevalence of Female Sexual Dysfunctions (FSD) in T1DM ranges from $18 \%$ to $71 \%$, whereas in $\mathrm{T} 2 \mathrm{DM}$ there is a more heterogeneous prevalence, ranging from $12 \%$ to $88 \%$ [18]. The pathophysiological correlates of FSD in metabolic disorders, like diabetes, are far from being elucidated. Nevertheless, as opposed to the male counterpart [50,51], in diabetic female population, SD seems to be more strongly related to psychological factors and depressed mood than to metabolic alterations per se. In particular, hyperglycemia and neurovascular alterations, as well as psychological disorders or recurrent genital infections, common in female diabetic patients, could have detrimental effects on sexual function [52].

All the domains of sexual cycle in women including desire, arousal, lubrication, orgasm and satisfaction were reported to be affected in both T1DM and T2DM patients. However, a recent systemic review suggests a greater impact of DM on desire than on the other sexual domains [53]. Genital arousal and lubrication are neuro-vascular events that represent an interplay between smooth muscle relaxation and contraction, similar to what happens for male. Accordingly, similar to what observed for ED, genital arousal disorder in diabetic women might be related to neurovascular alterations due to chronic hyperglycemia and vascular impairment in genital districts with altered genital response to sexual stimuli [54]. Based on the concept that sexual satisfaction in women is more dependent on psychological and relationship factors than to biological ones, a previous study failed to demonstrate that reduced sexual satisfaction at baseline could predict the onset of major cardiovascular events in women [55]. As reported for men, also hormonal milieu can affect sexuality in women with DM. Available data are mainly derived from animal models. Insulin and insulin-like growth factors (IGFs) can regulate the activities of aromatase and $3 \beta$-hydroxysteroid dehydrogenase, which are involved in steroid synthesis [56]. Some experimental data also suggest that insulin can contribute in maintaining estrogen receptor expression at the hypothalamus level, having a role in lordosis and solicitation behavior in female rats [57]. In addition, peripherally, both insulin and other growth factors stimulate the proliferation of mouse vaginal epithelial cells in culture and, in the vagina, estrogens seem to stimulate the production of IGF and IGF binding proteins $[58,59]$.

Sexual pain, is another important issue related to women sexuality. Unexplained vulvodynia has been proposed as an unrecognized sign of diabetic neuropathic syndrome [60]. In a recent consensus [61], however, DM was not considered among the potential pathogenic mechanisms causing/ worsening unexplained vulvodynia, suggesting that more studies are needed to better clarify this point.

\subsection{Effects of new anti-diabetic drugs on female sexuality}

Previous evidence demonstrated that weigh loss plays an important influence on the improvement of sexual function in T2DM women [62]. In fact, body image and body weight concerns have a negative impact in sexual functioning of DM patients [63]. Hence, physicians should consider the impact of losing weight in the choice of the most appropriate glucose-lowering therapies in female patients complying of sexual dysfunction.

As reported above, several drugs are available for T2DM treatment and some of them have a good impact on body weight like GLP-1RA and the most recent SGLT2i. Similar to what reported in men, it could be expected that the use of these drugs will have a positive effect on losing weight, resulting in better sexual outcomes. However, no studies have evaluated this point so far. 
Table 2 Characteristics of the studies evaluating the effect of new anti-diabetic drugs on male sexuality and hypogonadism

\begin{tabular}{|c|c|c|c|c|c|c|}
\hline Study & Drug & Model & Results/proposed mechanism & $\begin{array}{l}\text { Effect on male } \\
\text { sexual function }\end{array}$ & $\begin{array}{l}\text { Sexual } \\
\text { function }\end{array}$ & $\begin{array}{l}\text { Testosterone } \\
\text { levels }\end{array}$ \\
\hline $\begin{array}{l}\text { Huang et al. } \\
\text { (2012) [42] }\end{array}$ & DPP4i & Mouse & $\begin{array}{l}\text { Increse of release and mobilization of circulating endothelial } \\
\text { progenitor cells, through eNOS-related pathway }\end{array}$ & $\begin{array}{l}\text { Improvement of } \\
\text { erectile function }\end{array}$ & + & N/A \\
\hline $\begin{array}{l}\text { Harmar et al. } \\
\text { (2012) [43] }\end{array}$ & DPP4i & Mouse & $\begin{array}{l}\text { Improved endothelial function through pituitary adenylate } \\
\text { cyclase-activating polypeptide and VEGF related vasore- } \\
\text { laxation }\end{array}$ & $\begin{array}{l}\text { Improvement of } \\
\text { erectile function }\end{array}$ & + & N/A \\
\hline $\begin{array}{l}\text { Matsubara } \\
\text { et al. } \\
\text { (2012) [44] }\end{array}$ & DPP4i & Mouse & Antiatherogenic effects & $\begin{array}{l}\text { Improvement of } \\
\text { erectile function }\end{array}$ & + & N/A \\
\hline $\begin{array}{l}\text { Assaly et al. } \\
\text { (2012) [45] }\end{array}$ & SGLT2i & Mouse & $\begin{array}{l}\text { Increased NO mediated relaxation of erectile tissue; no } \\
\text { interference with sildenafil }\end{array}$ & $\begin{array}{l}\text { Improvement of } \\
\text { erectile function }\end{array}$ & + & N/A \\
\hline $\begin{array}{l}\text { Ahangarpour } \\
\text { et al. } \\
\text { (2014) [46] }\end{array}$ & GLP1RA & Mouse & $\begin{array}{l}\text { Increased testosterone and testis weight and volume in } \\
\text { ageing mouse model }\end{array}$ & $\begin{array}{l}\text { Improvement of } \\
\text { sexual hormones/ } \\
\text { erectile function }\end{array}$ & + & + \\
\hline $\begin{array}{l}\text { Shao et al. } \\
\text { (2018) [47] }\end{array}$ & GLP1RA & $\begin{array}{l}\text { T2DM } \\
\text { patients }\end{array}$ & $\begin{array}{l}\text { Exenatide }+ \text { metformin reduced waist circumference and } \\
\text { increased testosterone and sexual function compared to } \\
\text { glimepiride }+ \text { metformin }\end{array}$ & $\begin{array}{l}\text { Improved sexual } \\
\text { hormones/- } \\
\text { function }\end{array}$ & + & + \\
\hline $\begin{array}{l}\text { Jensterle } \\
\quad \text { et al. } \\
\text { (2019) }[48]\end{array}$ & GLP1RA & $\begin{array}{l}\text { Obese } \\
\text { hypogona- } \\
\text { dal } \\
\text { patients }\end{array}$ & $\begin{array}{l}\text { Liraglutide treated subjects lost weight and had increased } \\
\text { testosterone as well as improved sexual function }\end{array}$ & $\begin{array}{l}\text { Improved sexual } \\
\text { hormones/- } \\
\text { function }\end{array}$ & + & + \\
\hline $\begin{array}{l}\text { Giagulli et al. } \\
\text { (2015) [49] }\end{array}$ & GLP1RA & $\begin{array}{l}\text { Obese T2DM } \\
\text { patients }\end{array}$ & $\begin{array}{l}\text { Liraglutide in addition to testosterone replacement therapy } \\
\text { and metformin, further improved total testosterone, } \\
\text { metabolic control and erectile function }\end{array}$ & $\begin{array}{l}\text { Improved sexual } \\
\text { hormones/- } \\
\text { function }\end{array}$ & + & + \\
\hline
\end{tabular}

$D P P 4 i$ Inhibitors of dipeptidyl peptidase 4; SGLT2i Sodium-glucose co-transporter-2 inhibitors; GLP1RA Glucagon-like peptide-1 receptor agonists

\section{DM genitourinary tract infections}

Another complication in DM is the possibility to contract common infections, compared with patients without diabetes [64]. Urinary tract infections (UTI) and mucosal candidiasis are quite common and frequently more severe in people with diabetes than in the general population. Several studies have documented an association between the degree of glycemic control and the incidence or severity of infectious complications but the relationship between DM, hyperglycemia, immune function and infections is complex and many issues remain unresolved [65]. In this section, a summary of the impact of the most common UTI observed in DM population and their relationship with male and female sexual function will be analyzed. In addition, the possible contribution of SGLT2i on UTI will be also addressed.

\subsection{Epidemiological data}

The prevalence of asymptomatic bacteriuria (ASB) has been reported to range between 8 and $26 \%$ in patients with DM [66], without a clear association with metabolic control. Furthermore, meta-analytic data estimated the risk for ASB to be three times more common in diabetic patients compared
Fig. 1 Summary of the effects of novel anti-hyperglicemic drugs. DPP4-Inhibitors of dipeptidyl peptidase 4; SGLT2i- Sodiumglucose co-transporter-2 inhibitors; GLP1RA-Glucagon-Like Peptide 1 Receptor Agonists

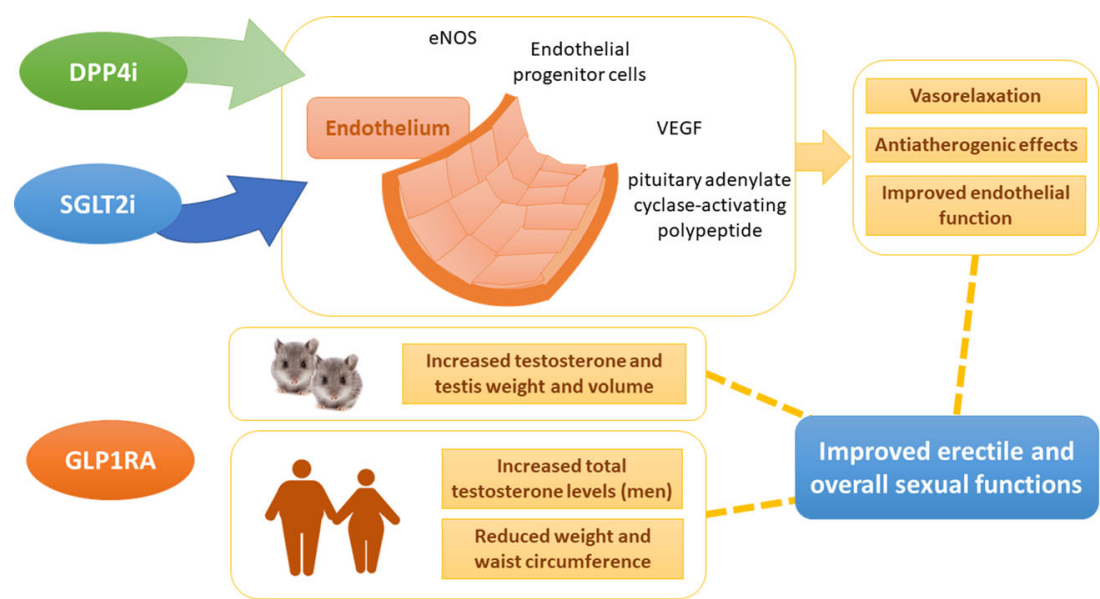


to the controls ( $12.2 \%$ vs. $4.5 \%$ ) [66]. The same study showed a higher risk in men compare to women [66].

UTI are one the most common infections in diabetes patients, with a reported incidence of 12.2 per 100 person-years for diabetic women, compared to 6.7 for non-diabetic women (RR 1.8; 95\% CI 1.2-2.7) [67]. The risk was tightly related to diabetes duration and was lower in men compared to women [67].

Patients with poorly controlled DM, are more prone to develop genital mycotic infections. Candida albicans is the most common pathogen causing balanitis and it is also the dominant cause of vulvovaginal candidiasis in women with diabetes [68].

Male Accessory Gland Inflammations/Infections (MAGI) represents another group of conditions frequently associated with DM. Condorelli et al. [69] reported an increased frequency of MAGI (about 43\%) among patients with T2DM, suggesting that MAGI may represent a possible undiagnosed complication of the diabetic population. In addition, La Vignera et al., [70] further reported peculiar ultrasound characteristics (lack of reduction of interparietal thickness after ejaculation and alteration of the relationship between glandular fund and body) of the seminal vesicles in DM patients, particularly among those with diabetic autonomic neuropathy, suggestive of functional atony [71].

\subsection{Impact on male and female sexual function}

Whereas acute and symptomatic UTI, as well as recurrent genital mycotic infections, have an obvious detrimental negative effect on male and female sexual function, the role of ASB and chronic abacterial MAGI is more conflicting. However, it has been suggested that recurrent infections can contribute to the development of low urinary tract symptoms (LUTS), in turn showing an independent association with ED $[72,73]$. Similarly, an increasing body of evidence supports an association between Lower Urinary Tract Dysfunction (LUTD) and FSD [74]. In particular, the presence of urinary incontinence (UI) (tightly associated with DM) and UTI doubles the risk for reduced libido compared to non-incontinent women, increasing vaginal dryness and dyspareunia [74]. In greater detail, women with detrusor overactivity and associated UI had the greatest degree of sexual dysfunction. While pure urgency UI is a risk factor for decreased lubrication and increased coital pain, mixed UI was associated with less sexual satisfaction [75].

\subsection{Impact of SGLT2i on male and female genitourinary tract infections}

Clinical trials have shown that SGLT2i are generally well tolerated. However, due to their mechanism of action, they are associated with an increased risk for genital mycotic infections, or serious adverse events, such as serious UTI. The increased risk of genital mycotic infections is likely to be related to the presence of urinary glucose, although no definitive dose relationship between incidence of infection and SGLT2 inhibitor treatment has been established to date. Genital mycotic infections associated with SGLT2i occurred more commonly in females and patients with a history of such infections [76-78]. Post-marketing reports have led to a warning from the Food and Drug Administration (FDA) about the possibility of severe urinary tract infection and pyelonephritis in patients treated with SGLT2i [79]. Health care professionals have been advised to evaluate patients for signs and symptoms of UTIs and GI and treat such infections promptly, if indicated.

\section{Conclusions}

Sexual dysfunctions are frequently observed in men and women with DM. ED should be routinely investigated in all men, since it is an early marker of forthcoming CVD. In addition, either in men or women sexual dysfunction can severely impair quality of life, resulting in worse metabolic control and poor therapeutic compliance. An early identification of the problems, and an adequate discussion, can lead to a virtuous cycle, allowing lifestyle modifications and better glycometabolic control. While the use of one of the most widely prescribed drugs to treat T2DM, metformin, is known to have a beneficial effect on male and female reproductive function, other drugs commonly used in more complicated forms, such as insulin and sulfonylureas, may have a negative effect on weight and thus on gonadal and sexual function. The novel classes of antihyperglycemic drugs, have shown promising metabolic effects: the positive (GLP1RA and SGLT2i) or neutral (DPP4i) effect on weight could be an interesting, though indirect, way to improve the gonadal and sexual function in diabetic subjects complaining of sexual dysfunction.

Acknowledgements This work was supported by a non-conditioned contribution of MSD Italia.

\section{Compliance with ethical standards}

Conflict of interest The authors declare that they have no conflict of interest.

\section{References}

1. Lozano R, Naghavi M, Foreman K, Lim S, Shibuya K, et al. Global and regional mortality from 235 causes of death for 20 age groups in 1990 and 2010: a systematic analysis for the global burden of disease study 2010. Lancet. 2013;380:2095-128. 
2. Guariguata L, Whiting D, Hambleton I, Beagley J, Linnenkamp U, et al. Global estimates of diabetes prevalence for 2013 and projections for 2035 for the IDF diabetes atlas. Diabetes Res Clin Pract. 2013.

3. (2013) International Diabetes Federation. IDF Diabetes Atlas 6th edn. International Diabetes Federation Brussels Belgium.

4. Puhl RM, Heuer CA. The stigma of obesity: a review and update. Obesity (Silver Spring). 2009;17:941-64.

5. Schwingshack1 HG, Lampousi AM, et al. Food groups and risk of type 2 diabetes mellitus: a systematic review and meta-analysis of prospective studies. Eur J Epidemiol. 2017;32:363-75.

6. Becerra-Tomás N, Blanco Mejía S, Viguiliouk E, et al. Mediterranean diet, cardiovascular disease and mortality in diabetes: a systematic review and meta-analysis of prospective cohort studies and randomized clinical trials. Crit Rev Food Sci Nutr. 2019 Jan;24:1-21 [Epub ahead of print].

7. The Action to Control Cardiovascular Risk in Diabetes Study Group. Effects of intensive glucose lowering in type 2 diabetes. $\mathrm{N}$ Engl J Med. 2008;358:2545-59.

8. Duckworth W, Abraira C, Moritz T, Reda D, Emanuele N, Reaven $\mathrm{PD}$, et al. Glucose control and vascular complications in veterans with type 2 diabetes. N Engl J Med. 2009;360:129-39.

9. The ADVANCE Collaborative Group. Intensive blood glucose control and vascular outcomes in patients with type 2 diabetes. $\mathrm{N} \mathrm{Engl} \mathrm{J}$ Med. 2008;358:2560-72.

10. Turnbull FM, Abraira C, Anderson RJ, et al. Intensive glucose control and macrovascular outcomes in type 2 diabetes. Diabetologia. 2009;52:2288-98.

11. Inzucchi SE, Bergenstal RM, Buse JB, Diamant M, Ferrannini E, Nauck M, et al. Management of hyperglycemia in type 2 diabetes, 2015: a patient-centered approach: update to a position statement of the American Diabetes Association and the European Association for the Study of diabetes. Diabetes Care. 2015;38:140-9.

12. Ferrannini E, Solini A. SGLT2 inhibition in diabetes mellitus: rationale and clinical prospects. Nat Rev Endocrinol. 2012;8:495502.

13. Jingfan Z, Ling L, Cong L, Ping L, Yu C. Efficacy and safety of sodium-glucose cotransporter-2 inhibitors in type 2 diabetes mellitus with inadequate glycemic control on metformin: a metaanalysis. Arch Endocrinol Metab. 2019. https://doi.org/10.20945/ 2359-3997000000146.

14. Zinman B, Wanner C, Lachin JM, Fitchett D, Bluhmki E, Hantel S, et al. EMPA-REG OUTCOME investigators Empaglifozin, cardiovascular outcomes, and mortality in type 2 diabetes. N Engl J Med. 2015;373:2117-28.

15. Neal B, Perkovic V, Mahaffey KW, de Zeeuw D, Fulcher G, Erondu $\mathrm{N}$, et al. Canagliflozin and cardiovascular and renal events in type 2 diabetes. N Engl J Med. 2017;377(7):644-57.

16. Wiviott SD, Raz I, Bonaca MP, Mosenzon O, Kato ET, Cahn A, et al. Dapagliflozin and Cardiovascular Outcomes in Type 2 Diabetes. N Engl J Med. 2019;380(4):347-57.

17. Monami M, Zannoni S, Pala L, Silverii A, Andreozzi F, Sesti G, et al. Effects of glucagon-like peptide-1 receptor agonists on mortality and cardiovascular events: a comprehensive meta-analysis of randomized controlled trials. Int J Cardiol. 2017 Aug 1;240:41421.

18. Maseroli E, Scavello I, Vignozzi L. Cardiometabolic risk and female sexuality-part I. risk factors and potential pathophysiological underpinnings for female vasculogenic sexual dysfunction syndromes. Sex Med Rev. 2018;6(4):508-24. https://doi.org/10.1016/ j.sxmr.2018.02.009.

19. Kouidrat Y, Pizzol D, Cosco T, Thompson T, Carnaghi M, Bertoldo A, et al. High prevalence of erectile dysfunction in diabetes: a systematic review and meta-analysis of 145 studies. Diabet Med. 2017;34:1185-92.
20. Corona G, Bianchini S, Sforza A, Vignozzi L, Maggi M. Hypogonadism as a possible link between metabolic diseases and erectile dysfunction in aging men. Hormones (Athens). 2015;14(4): $569-78$.

21. Yamada T, Hara K, Umematsu H, Suzuki R, Kadowaki T. Erectile dysfunction and cardiovascular events in diabetic men: a metaanalysis of observational studies. PLoS One. 2012;7(9):e43673.

22. Fedele D, Coscelli C, Santeusanio F, Bortolotti A, Chatenoud L, Colli E, et al. Erectile dysfunction in diabetic subjects in Italy. Gruppo Italiano Studio Deficit Erettile nei Diabetici. Diabetes Care. 1998;21:1973-7.

23. Corona G, Giorda CB, Cucinotta D, Guida P, Nada E, Gruppo di studio SUBITO-DE. Sexual dysfunction at the onset of type 2 diabetes: the interplay of depression, hormonal and cardiovascular factors. J Sex Med. 2014;11:2065-73.

24. Fedele D, Coscelli C, Cucinotta D, Forti G, Santeusanio F, Viaggi $\mathrm{S}$, et al. Incidence of erectile dysfunction in Italian men with diabetes. J Urol. 2001;166:1368-71.

25. Derby CA, Araujo AB, Johannes CB, Feldman HA, McKinlay JB. Measurement of erectile dysfunction in population-based studies: the use of a single question self-assessment in the Massachusetts male aging study. Int J Impot Res. 2000;12:197-204.

26. De Berardis G, Pellegrini F, Franciosi M, Belfiglio M, Di Nardo B, Greenfield S; QuED Study Group et al. Clinical and psychological predictors of incidence of self-reported erectile dysfunction in patients with type 2 diabetes. J Urol. 2007;177:252-257.

27. Klein R, Klein BE, Moss SE. Ten-year incidence of self-reported erectile dysfunction in people with long-term type 1 diabetes. J Diabetes Complications. 2005;19:35-41.

28. Diabetes Association. (2007) Undersøgelse af rejsningsbesvær blandt diabetikere (Study of erectile dysfunction among diabetes patients). Available at: http://www.diabetes.dk/media/352262/ Rejsningsbesv\%C3\%A6r_blandt_diabetikere.pdf (Accessed 15 Feb 2016).

29. Bjerggaard M, Charles M, Kristensen E, Lauritzen T, Sandbæk A, Giraldi A. Prevalence of sexual concerns and sexual dysfunction among sexually active and inactive men and women with screendetected type 2 diabetes. Sex Med. 2015;3:302-10.

30. Corona G, Rastrelli G, Filippi S, Vignozzi L, Mannucci E, Maggi M. Erectile dysfunction and central obesity: an Italian perspective. Asian J Androl. 2014;16(4):581-91.

31. Gianatti EJ, Grossmann M. Testosterone deficiency in men with type 2 diabetes: pathophysiology and treatment. Diabet Med. 2019. https://doi.org/10.1111/dme.13977.

32. Corona G, Maseroli E, Rastrelli G, Francomano D, Aversa A, Hackett GI, et al. Is late-onset hypogonadotropic hypogonadism a specific age-dependent disease, or merely an epiphenomenon caused by accumulating disease-burden? Minerva Endocrinol. 2016:41:196-210

33. Ho CH, Yu HJ, Wang CY, Jaw FS, Hsieh JT, Liao WC, et al. Prediabetes is associated with an increased risk of testosterone deficiency, independent of obesity and metabolic syndrome. PLoS One. $2013 ; 8: \mathrm{e} 74173$.

34. Camacho EM, Huhtaniemi IT, O'Neill TW, Finn JD, Pye SR, Lee $\mathrm{DM}$, et al. Age-associated changes in hypothalamic-pituitarytesticular function in middle-aged and older men are modified by weight change and lifestyle factors: longitudinal results from the European Male Ageing Study. Eur J Endocrinol. 2013;168:445-55.

35. Morelli A, Filippi S, Comeglio P, Sarchielli E, Cellai I, Pallecchi M, et al. Physical activity counteracts metabolic syndrome-induced hypogonadotropic hypogonadism and erectile dysfunction in the rabbit. Am J Physiol Endocrinol Metab. 2019 Mar 1;316(3): E519-35.

36. Navarro G, Allard C, Xu W, Mauvais-Jarvis F. The role of androgens in metabolism, obesity, and diabetes in males and females. Obesity (Silver Spring). 2015;23:713-9. 
37. Kelly DM, Akhtar S, Sellers DJ, Muraleedharan V, Channer KS, Jones TH. Testosterone differentially regulates targets of lipid and glucose metabolism in liver, muscle and adipose tissues of the testicular feminised mouse. Endocrine. 2016;54:504-15.

38. Corona G, Isidori AM, Aversa A, Burnett AL, Maggi M. Endocrinologic control of men's sexual desire and arousal/erection. J Sex Med. 2016 Mar;13(3):317-37.

39. Felici F, Bazzucchi I, Sgrò P, Quinzi F, Conti A, Aversa A, et al. Acute severe male hypo-testosteronemia affects central motor command in humans. J Electromyogr Kinesiol. 2016 Jun;28:184-92.

40. Isidori AM, Balercia G, Calogero AE, Corona G, Ferlin A, Francavilla $\mathrm{S}$, et al. Outcomes of androgen replacement therapy in adult male hypogonadism: recommendations from the Italian Society of Endocrinology. J Endocrinol Investig. 2015 Jan;38(1): 103-12.

41. Rastrelli G, Maggi M, Corona G. Pharmacological management of late-onset hypogonadism. Expert Rev Clin Pharmacol. 2018 Apr;11(4):439-58.

42. Huang CY, Shih CM, Tsao NW, Lin YW, Huang PH, Wu SC, et al. Dipeptidyl peptidase-4 inhibitor improves neovascularization by increasing circulating endothelial progenitor cells. Br J Pharmacol. 2012;167(7):1506-19. https://doi.org/10.1111/j.14765381.2012.02102.x.

43. Harmar AJ, Fahrenkrug J, Gozes I, Laburthe M, May V, Pisegna $\mathrm{JR}$, et al. Pharmacology and functions of receptors for vasoactive intestinal peptide and pituitary adenylate cyclase-activating polypeptide: IUPHAR review 1. Br J Pharmacol. 2012;166(1):4-17. https://doi.org/10.1111/j.1476-5381.2012.01871.x.

44. Matsubara J, Sugiyama S, Sugamura K, Nakamura T, Fujiwara Y, Akiyama E, et al. A dipeptidyl peptidase-4 inhibitor, des-fluorositagliptin, improves endothelial function and reduces atherosclerotic lesion formation in apolipoprotein E-deficient mice. J Am Coll Cardiol. 2012;59(3):265-76. https://doi.org/10.1016/j.jacc.2011. 07.053 .

45. Assaly R, Gorny D, Compagnie S, Mayoux E, Bernabe J, Alexandre L, et al. The favorable effect of empagliflozin on erectile function in an experimental model of type 2 diabetes. J Sex Med. 2012;15(9):1224-34. https://doi.org/10.1016/j.jsxm.2018.07.002.

46. Ahangarpour A, Oroojan AA, Heidari H. Effects of exendin-4 on male reproductive parameters of d-galactose induced aging mouse model. World J Mens Health. 2014;32(3):176-83. https://doi.org/ 10.5534/wjmh.2014.32.3.176

47. Shao N, Yu XY, Yu YM, Li BW, Pan J, Wu WH, et al. Short-term combined treatment with exenatide and metformin is superior to glimepiride combined metformin in improvement of serum testosterone levels in type 2 diabetic patients with obesity. Andrologia. 2018;50(7):e13039. https://doi.org/10.1111/and.13039.

48. Jensterle M, Podbregar A, Goricar K, et al. Effects of liraglutide on obesity-associated functional hypogonadism in men. Endocr Connect. 2019. https://doi.org/10.1530/EC-18-0514.

49. Giagulli VA, Carbone MD, Ramunni MI, Licchelli B, de Pergola G, Sabbà $\mathrm{C}$, et al. Adding liraglutide to lifestyle changes, metformin and testosterone therapy boosts erectile function in diabetic obese men with overt hypogonadism. Andrology. 2015;3:1094-103. https://doi.org/10.1111/andr.12099.

50. Corona G, Fagioli G, Mannucci E, Romeo A, Rossi M, Lotti F, et al. Penile doppler ultrasound in patients with erectile dysfunction (ED): role of peak systolic velocity measured in the flaccid state in predicting arteriogenic ED and silent coronary artery disease. J Sex Med. 2008;5(11):2623-34. https://doi.org/10.1111/j.17436109.2008.00982.x

51. Rastrelli G, Corona G, Lotti F, Aversa A, Bartolini M, Mancini M, et al. Flaccid penile acceleration as a marker of cardiovascular risk in men without classical risk factors. J Sex Med. 2014;11(1):17386. https://doi.org/10.1111/jsm.12342.
52. Kizilay F, Gali HE, Serefoglu EC. Diabetes and sexuality. Sex Med Rev. 2017;5(1):45-51. https://doi.org/10.1016/j.sxmr.2016.07.002.

53. Giraldi A, Kristensen E. Sexual dysfunction in women with diabetes mellitus. J Sex Res. 2010;47(2):199-211. https://doi.org/10. 1080/00224491003632834.

54. Althof SE, Meston CM, Perelman MA, Handy AB, Kilimnik CD, Stanton AM. Opinion paper: on the diagnosis/classification of sexual arousal concerns in women. J Sex Med. 2017;14(11):1365-71. https://doi.org/10.1016/j.jsxm.2017.08.013.

55. McCall-Hosenfeld JS, Freund KM, Legault C, Jaramillo SA, Cochrane BB, Manson JE, et al. Sexual satisfaction and cardiovascular disease: the Women's Health Initiative. Am J Med. 2008;121(4):295-301. https://doi.org/10.1016/j.amjmed.2007.11. 013.

56. Nestler JE, Strauss JF 3rd. Insulin as an effector of human ovarian and adrenal steroid metabolism. Endocrinol Metab Clin N Am. 1991;20(4):807-23.

57. Ahdieh HB, Hamilton JM, Wade GN. Copulatory behavior and hypothalamic estrogen and progestin receptors in chronically insulin-deficient female rats. Physiol Behav. 1983;31(2):219-23.

58. Ozawa S, Iguchi T, Takemura KK, Bern HA. Effect of certain growth factors on proliferation in serum-free collagen gel culture of vaginal epithelial cells from prepuberal mice exposed neonatally to diethylstilbestrol. Proc Soc Exp Biol Med. 1991;198(2):760-3.

59. Suzuki A, Urushitani H, Watanabe H, Sato T, Iguchi T, Kobayashi $\mathrm{T}$, et al. Comparison of estrogen responsive genes in the mouse uterus, vagina and mammary gland. J Vet Med Sci. 2007;69(7): 725-31.

60. Kalra B, Kalra S, Bajaj S. Vulvodynia: an unrecognized diabetic neuropathic syndrome. Indian J Endocrinol Metab. 2013 Sep; 17(5): 787-9. https://doi.org/10.4103/2230-8210.117193.

61. Bornstein J, Goldstein AT, Stockdale CK, Bergeron S, Pukall C, Zolnoun D, et al. 2015 ISSVD, ISSWSH, and IPPS consensus terminology and classification of persistent vulvar pain and Vulvodynia. J Sex Med. 2016;13(4):607-12. https://doi.org/10. 1016/j.jsxm.2016.02.167.

62. Wing RR, Bond DS, Gendrano IN 3rd, Wadden T, Bahnson J, Lewis CE, et al. Effect of intensive lifestyle intervention on sexual dysfunction in women with type 2 diabetes: results from an ancillary look AHEAD study. Diabetes Care. 2013;36(10):2937-44. https://doi.org/10.2337/dc13-0315.

63. Ferraresi SR, Lara LA, Reis RM, Rosa E Silva AC. Changes in sexual function among women with polycystic ovary syndrome: a pilot study. J Sex Med. 2013;10(2):467-73. https://doi.org/10.1111/ jsm. 12011.

64. Muller LM, Gorter KJ, Hak E, Goudzwaard WL, Schellevis FG, Hoepelman AI, et al. Increased risk of common infections in patients with type 1 and type 2 diabetes mellitus. Clin Infect Dis. 2005;41(3):281-8.

65. Pearson-Stuttard J, Blundell S, Harris T, Cook DG, Critchley J. Diabetes and infection: assessing the association with glycaemic control in population-based studies. Lancet Diabetes Endocrinol. 2016;4(2):148-58.

66. Renko M, Tapanainen P, Tossavainen P, Pokka T, Uhari M. Metaanalysis of the significance of asymptomatic bacteriuria in diabetes. Diabetes Care. 2011;34(1):230-5.

67. Shah BR, Hux JE. Quantifying the risk of infectious diseases for people with diabetes. Diabetes Care. 2003;26(2):510-3.

68. Nyirjesy P, Sobel JD. Genital mycotic infections in patients with diabetes. Postgrad Med. 2013;125(3):33-46.

69. Condorelli RA, Calogero AE, Vicari E, Duca Y, Favilla V, et al. Prevalence of MAGI in patients with type 2 diabetes mellitus. J Endocrinol Invest. 2013;36:770-4.

70. La Vignera S, Condorelli RA, Di Mauro M, D’Agata R, Vicari E, et al. Seminal vesicles and diabetic neuropathy: ultrasound evaluation. J Androl. 2011;32:478-83. 
71. La Vignera S, Vicari E, Condorelli R, D'Agata R, Calogero AE. Ultrasound characterization of the seminal vesicles in infertile patients with type 2 diabetes mellitus. Eur J Radiol. 2011;80:e64-7.

72. De Nunzio C, Roehrborn CG, Andersson KE, McVary KT. Erectile dysfunction and lower urinary tract symptoms. Eur Urol Focus. 2017;3:352-63.

73. Calogero AE, Duca Y, Condorelli RA, La Vignera S. Male accessory gland inflammation, infertility, and sexual dysfunctions: a practical approach to diagnosis and therapy. Andrology. 2017 Nov;5(6):1064-72.

74. Rantell A, Apostolidis A, Anding R, Kirschner-Hermanns R, Cardozo L. How does lower urinary tract dysfunction affect sexual function in men and women? ICI-RS 2015-part 1. Neurourol Urodyn. 2017;36(4):949-52. https://doi.org/10.1002/nau.23040.

75. Su CC, Sun BY, Jiann BP. Association of urinary incontinence and sexual function in women. Int J Urol. 2015;22:109-13.

76. Janssen Pharmaceuticals, Inc. Prescribing information (05/ 2016): INVOKANA (canagliflozin) tablets, for oral use. Available from http://www.accessdata.fda.gov/drugsatfda_docs/label/2016/ 204042s015s019lbl.pdf. Accessed 20 Aug 2016.
77. AstraZeneca Pharmaceuticals LP. Prescribing information (06/ 2016): FARXIGA (dapagliflozin) tablets, for oral use. Available from http://www.accessdata.fda.gov/drugsatfda_docs/label/2016/ 202293s009lbl.pdf. Accessed 10 Aug 2016.

78. Boehringer Ingelheim Pharmaceuticals Inc. Prescribing information (07/2016): JARDIANCE (empagliflozin) tablets, for oral use. Available from http://docs.boehringer-ingelheim.com/ Prescribing\%20Informati.

79. U.S. Food and Drug Administration. (2015) Drug safety communication: FDA revises labels of SGLT2 inhibitors for diabetes to include warnings about too much acid in the blood and serious urinary tract infections, Available from http://www.fda.gov/ downloads/Drugs/DrugSafety/UCM475487.pdf. Accessed 18 Jan 2016 .

Publisher's note Springer Nature remains neutral with regard to jurisdictional claims in published maps and institutional affiliations. 